\title{
Rekayasa Perangkat Lunak Penjadwalan dan Pemesanan Iklan Radio (Studi Kasus : Radio Classy FM)
}

\author{
Anisya $^{1}$, Ersab Allazi $^{2}$ \\ 1,2 Fakultas Teknologi Industri, Institut Teknologi Padang \\ Jl. Gajah Mada Kandis Nanggalo, Padang, Sumatera Barat, 25173 \\ nisa.anisya@gmail.com ${ }^{1}$, allazie@yahoo.com ${ }^{2}$
}

\begin{abstract}
Abstrak - Banyak cara untuk bisa memasarkan atau mempromosikan sebuah produk maupun usaha, yaitu salah satunya dengan memasarkannya pada sebuah iklan di radio. Proses pemesanan iklan di radio biasanya diproses oleh seorang marketing. Dan pada saat sekarang ini proses yang dilakukan untuk pemesanan iklan masih dengan cara yang manual yaitu dengan cara costumer mendatangi kantor radio yang bersangkutan untuk melakukan pemesanan iklan. Hal ini kurang efektif karena marketing harus selalu berada dilokasi kantor agar proses pemesanan iklan dapat terlaksana. Oleh karena itu diperlukan sebuah aplikasi sistem informasi yang dapat menjembatani proses pemesanan iklan tersebut. Sehingga dengan adanya sistem informasi ini marketing dapat menginformasikan kepada costumer tentang ketersediaan tempat untuk beriklan tanpa harus memeriksa langsung ke stasiun radio tersebut.Dan costumer dapat melakukan transaksi pemesanan iklan hanya dengan perangkat mobile yang dia miliki. Hasil dari pembuatan sistem informasi ini diharapkan dapat membantu mempermudah kerja seorang marketing dalam menginformasikan tentang jadwal kosong yang ada pada radio tersebut dan dapat membantu penjadwalan dan pemesanan iklan yang efektif dan efisien..
\end{abstract}

Kata kunci - Sistem Informasi, Berbasis Mobile, Penjadwalan dan Pemesanan Iklan Radio

\section{PENDAHULUAN}

Iklan adalah kegiatan memberitahukan atau menginformasikan suatu hal, barang atau jasa melalui media massa baik online maupun offline. Dan salah satu media penyampaian iklan yang ada pada masa sekarang ini adalah radio.

Radio merupakan salah satu media massa penyampai informasi yang cukup banyak diminati oleh masyarakat pada saat sekarang ini. Radio berkaitan erat dengan kebutuan masyarakat, karena dapat memberikan informasi, hiburan dan pendidikan.Berbagai informasi dapat disampaikan dengan yang jelas dan dengan bahasa yang mudah dipahami masyarakat pada umumnya.

Hal yang menjadi latar belakang masalah dalam penelitian ini adalah saat ini bermacam costumer yang ingin memasarkan produknya pada stasiun radio Classy FM. Semakin banyak costumer yang ingin mengiklankan produknya, maka semakin padat juga penjadwalan yang ada pada stasiun radio Classy FM. Dan pada saat ini proses yang dilakukan untuk permintaan penjadwalan dan penyiaran iklan masih dilakukan secara manual yaitu seorang marketing harus memberikan informasi jadwal kosong untuk diinformasikan kepada costumer atau costumer tersebut harus mendatangi stasiun radio tersebut untuk mendapatkan informasi tentang jadwal yang kosong untuk di pesan oleh costumer. Dan proses pemesanan dan penjadwalan pada saat ini masih mengalami kesulitan, dikarenakan semuanya masih menggunakan aplikasi office dalam pemprosesannya.

Untuk lebih memudahkan para marketing memberikan informasi penjadwalan iklan serta untuk memudahkan costumer dalam melakukan pemesanan iklan tersebut, diperlukan sebuah sistem informasi yang dapat diakses melalui perangkat mobile yang dimiliki.Sehingga marketing dapat memberikan informasi tentang jadwal iklan, juga para costumer dapat melakukan pemesanan iklan dimana saja dan kapan saja ketika dibutuhkan.

\section{LANDASAN TEORI}

\section{A. Konsep Dasar Sistem}

Sistem adalah sekumpulan dari elemenelemen yang berinteraksi untuk mencapai suatu tujuan tertentu. Menurut [1], "Suatu sistem dapat didefinisikan sebagai suatu kesatuan yang teridiri dari dua atau lebih komponen atau subsistem yang berinteraksi untuk mencapai suatu tujuan".Ada beberapa elemen yang membentuk sebuah sistem, yaitu: tujuan, masukan, proses, keluaran, batas, mekanisme pengendalian dan umpan balik serta lingkungan. 


\section{B. Konsep Dasar Informasi}

Informasi adalah data yang telah diolah menjadi sebuah bentuk yang berarti bagi penerimanya dan bermanfaat dalam pengambilan keputusan saat ini atau mendatang

Keputusan dapat berkisar dari kepurtusan yang sederhana sampai keputusan strategi jangka panjang.Sedangkan parameter untuk mengukur nilai sebuah informasi tersebut, ditentukan dari dua hal pokok yatu manfaat (benevite) dan biaya (cost).Suatu informasi dikatakan berrnilai bila manfaatnya lebih efektif dibandingkan dengan biaya untuk mendapatkannya dan sebagian besar informasi tidak dapat ditaksir keuntungan dengan satuan nilai uang, tidak dapat ditaksir nilai efektifitasnya.

\section{Sistem Informasi}

Menurut Leitch Davis, sistem informasi adalah suatu sistem didalam sebuah organisasi yang mempertemukan kebutuhan pengolahan data transaksi harian yang mendukung operasi dan bersifat manajerial dan kegiatan strategis yang diperlukan bagi pihak luar tertentu.Operasi dasar dari sistem informasi terdiri dari empat dasar yaitu pengumpulan, mengolah, menyimpan dan menyebarkan informasi.Informasi mungkin dikumpulkan dari lingkungan dalam atau luar dan memungkinkan didistribusikan kedalam atau keluar organisasi.

Adapun kemampuan utama dari sistem informasi diantaranya:

a. Melaksanakan komputasi numerik yang bervolume besar dan berkecepatan tinggi.

b. Menyediakan komunikasi dalam organisasi atau antar organisasi yang mudah.

c. Menyimpan informasi dalam jumlah yang sangat besar dalam ruang yang kecil tetapi mudah diakses.

d. Memungkinkan pengaksesan informasi yang sangat banyak diseluruh dunia dengan cepat dan murah.

e. Meningkatkan efektifitas dan efisiensi orangorang yang bekerja pada suattu kelompok, tempat atau beberapa lokasi

f. Mengoptimalisasi proses-proses bisnis dan tugas-tugas yang dikerjakan secara manual.

g. Pembiayaan yang lebih murah dibandingkan dengan pengerjaan secara manual.

\section{Database}

Database adalah kumpulan data / informasi yang teratur berdasarkan kriteria tertentu yang saling berhubungan[2]. Dalam dunia komputer database bisa dikategorikan sangat spesial karena selalu menjadi hal utama dalam perancangan sistem computer. Tentunya ada alasan tertentu mengapa database menjadi prioritas tersendiri dalam kinerja diantaranya adalah : a. Database tidak hanya berisi data tetapi juga berisi rencana atau modal data.

b. Database dapat menjadi sumber utama yang digunakan secara bersama-sama oleh berbagai pemakai sesuai dengan kebutuhan.

\section{E. Normalisasi Database}

Proses normalisasi adalah proses pengelompokan data elemen menjadi tabel-tabel yang menunjukkan entity dan relasinya. Adapun tujuan dari normalisasi adalah sebagai berikut :

a. Untuk menghilangkan kerangkapan data.

b. Untuk mengurangi kompleksitas.

c. Untuk mempermudah pemodifikasi data.

Adapun proses dari normalisasi data itu adalah sebagai berikut :

1. Data diuraikan dalam bentuk tabel, selanjutnya dianalisa berdasarkan persyaratan tertentu ke beberapa tingkat.

2. Apabila tabel yang diuji belum memenuhi persyaratan tertentu, maka tabel tersebut perlu dipecah menjadi beberapa tabel yang lebih sederhana sampai memenuhi bentuk yang optimal.

\section{F. Context Diagram}

Pada Context Diagram ini menggambarkan garis besar dari Integrasi Sistem Informasi Penjadwalan dan Pemesanan Iklan Radio Classy FM

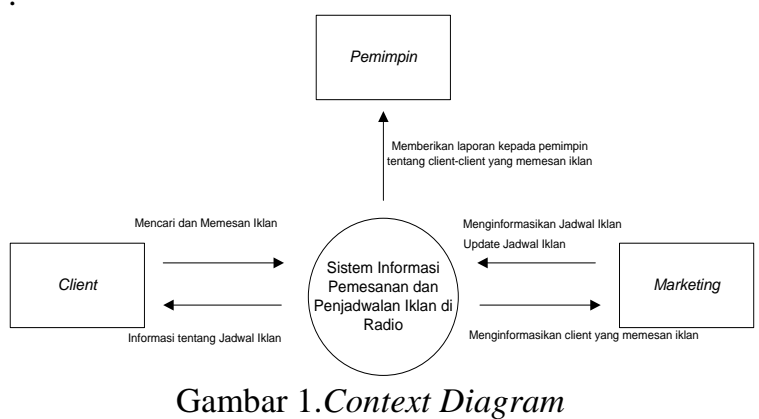

\section{G. ERD (Entity Relationship Diagram)}

Entity Relantionship Diagram adalah relasi yang berisikan komponen-komponen himpunan entitas dan himpunan relasi yang masing-masing dilengkapi dengan atribut-atribut.Dapat dilihat pada Gambar 2. 


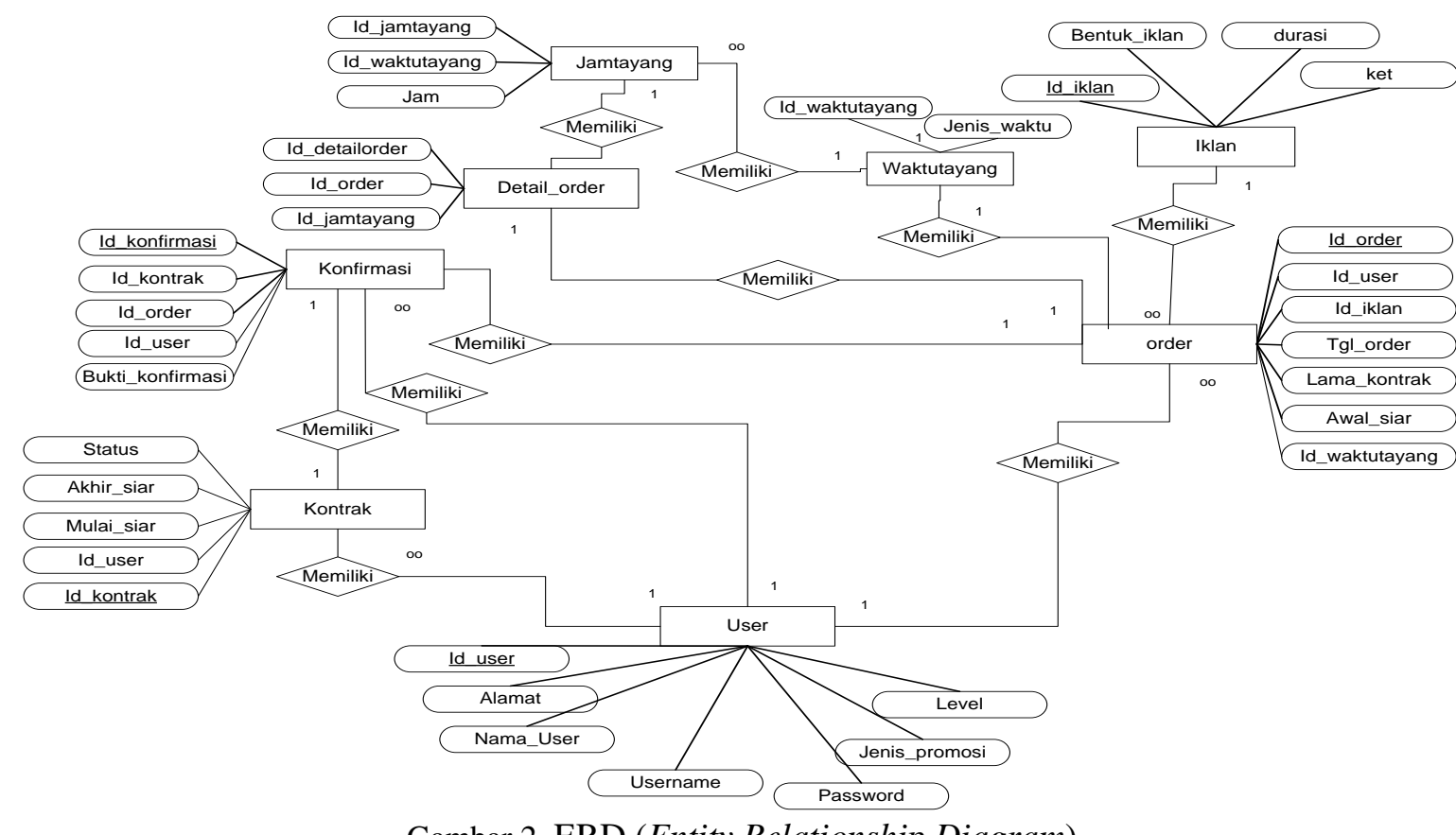

Gambar 2. ERD (Entity Relationship Diagram)

\section{H. Web Mobile}

Web Mobile bertujuan untuk mengakses layanan data secara wireless dengan menggunakan perangkat mobile seperti handphone, pda dan perangkat portable yang tersambung ke sebuah jaringan telekomunikasi selular. Mobile web yang diakses melalui perangkat mobile perlu dirancang dengan mempertimbangkan keterbatasan perangkat mobile seperti sebuah handphone yang memiliki sebuah layar dengan ukuran yang terbatas ataupun beberapa keterbatasan pada sebuah perangkat mobile.

Mobile Web umumnya berukuran ringan disetiap halamannya yang ditulis dengan Extensible Hypertext Markup Language (XHTML) atau Wireless Markup Language (WML) untuk mengirimkan konten ke perangkat mobile.Selain itu beberapa teknik seperti dengan menggunakan Adobe Flash Lite atau Sunâ€ J2ME yang memungkinkan untuk membuat perangkat mobile yang lebih bervariasi.

\section{PHP \& MySQL}

PHP: Hypertext Preprocessor adalah bahasa skrip yang dapat ditanamkan atau disisipkan ke dalam HTML. PHP banyak dipakai untuk memrogram situs web dinamis. PHP dapat digunakan untuk membangun sebuah CMS.

MySQL (bisa dibaca dengan mai-es-ki-el atau bisa juga mai-se-kuel) adalah suatu perangkat lunak database relasi (Relational Database Management System atau DBMS), seperti halnya ORACLE, POSTGRESQL, MSSQL, dan sebagainya. SQL merupakan singkatan dari Structure Query Language, didefinisikan sebagai suatu sintaks perintah-perintah tertentu atau bahasa program yang digunakan untuk mengelola suatu database. Jadi MySQL adalah softwarenya dan SQL adalah bahasa perintahnya[3].

\section{METODOLOGI PENELITIAN}

\section{A. Jenis Penelitian}

Jenis penelitian yang penulis lakukan ini adalah penelitian tentang sistem informasi penjadwalan dan pemesanan iklan pada Radio Classy FM. Yang bertujuan untuk menghasilkan sebuah sistem informasi yang berguna untuk mempermudah client maupun marketing dalam melakukan transaksi pemesanan iklan.

\section{B. Alat dan Bahan}

Alat dan bahan yang digunakan dalam perancangan sistem informasi ini adalah sebagai berikut :

1. Perangkat Keras (Hardware) a. Laptop Asus : Intel(R) Core(TM) i3-
2328M CPU @ 2.20GHz 2.20GHz
b. 2GB Memory
c. 500GB HDD

2. Perangkat Lunak (Software)
a. Sistem Operasi Windows8
b. Microsoft Office 2010
c. Microsoft Office Visio 2007
d. $X A M P P$ 
e. JetBrains PhpStorm 2016.1

f. CSS Boostrap

\section{Struktur Program}

Struktur program yang dimaksud yaitu untuk memberikan gambaran umum bagaimana bentuk dan model dari rancangan program yang akan dibuat.

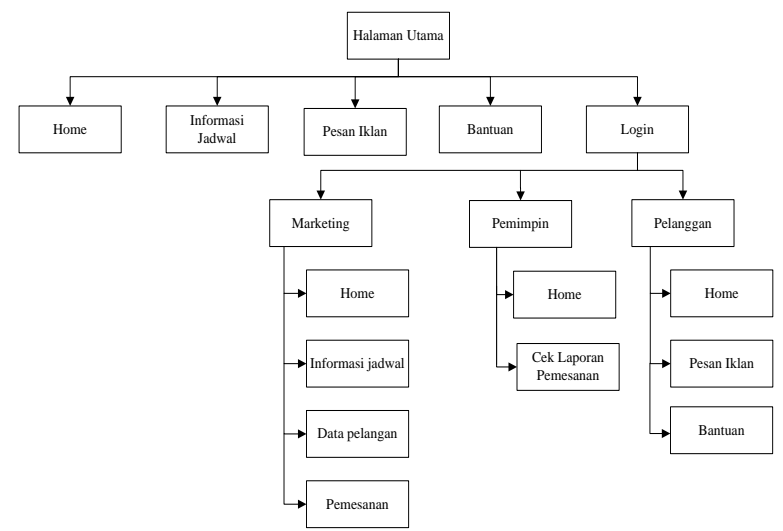

Gambar 3. Struktur Program

\section{Flowchart Sistem}

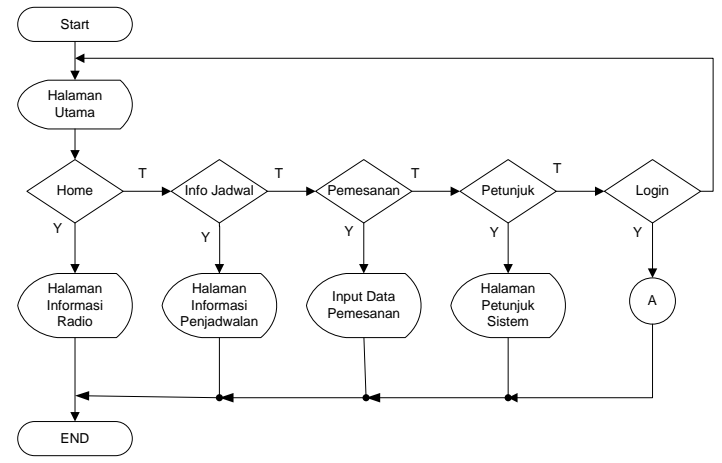

Gambar 4. Flowchart halaman utama

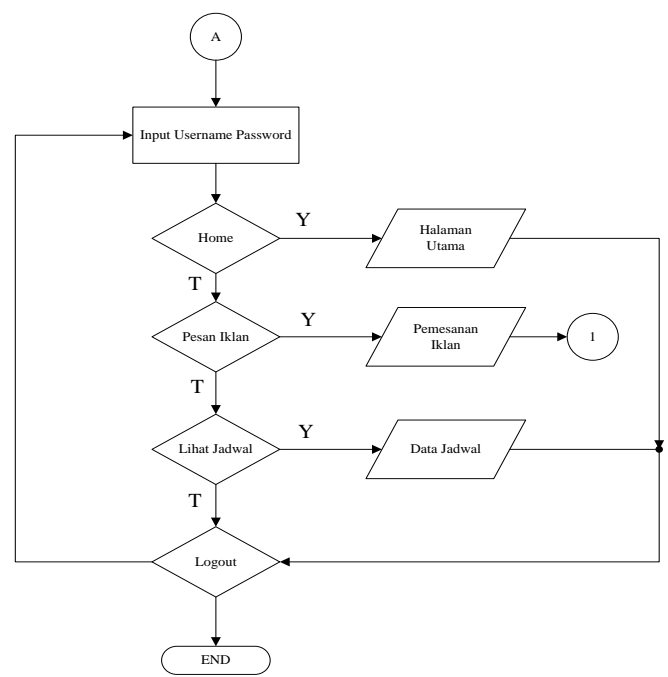

Gambar 5. Flowchart halaman Operator

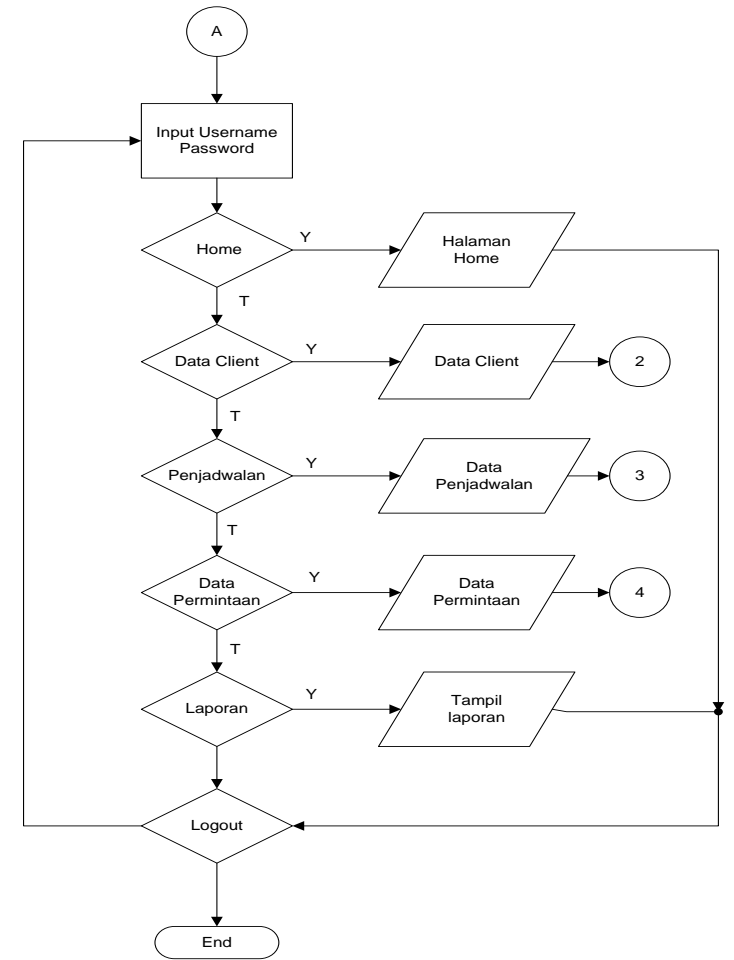

Gambar 6. Flowchart Halaman Marketing

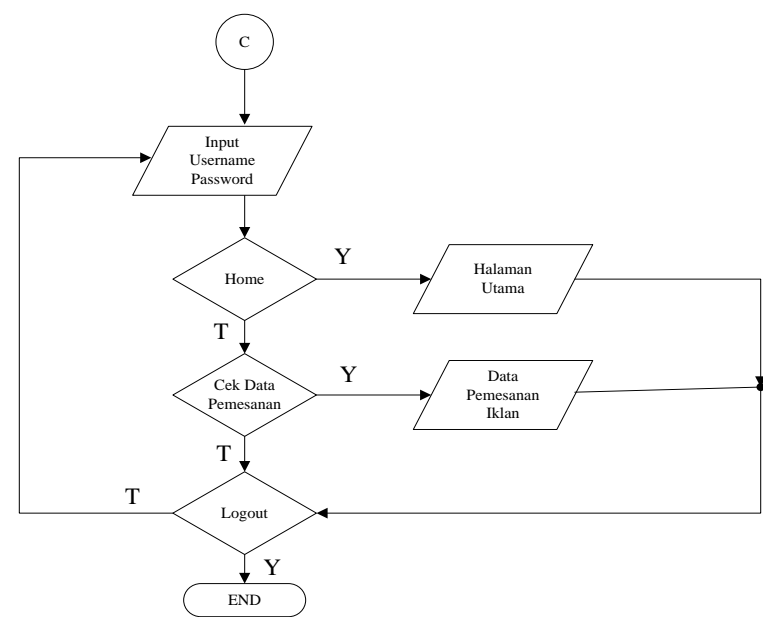

Gambar 7. Flowchart Halaman Pimpinan

\section{PEMBAHASAN}

Pada pembahasan dijelaskan secara lengkap bagaimana tampilan-tampilan layar pada program aplikasi Sistem Informasi penjadwalan dan pemesanan iklan radio :

\section{A. Halaman Utama User}

Halaman utama merupakan halaman yang pertama sekali tampil dan di akses oleh user atau pengguna pada website sistem informasi 
penjadwalan dan pemesanan iklan radio.Pada halaman utama terdapat menu-menu seperti menu Home, Informasi Jadwal, Pemesanan Iklan, Bantuan, dan menu login yang mana terlihat seperti pada Gambar 8.

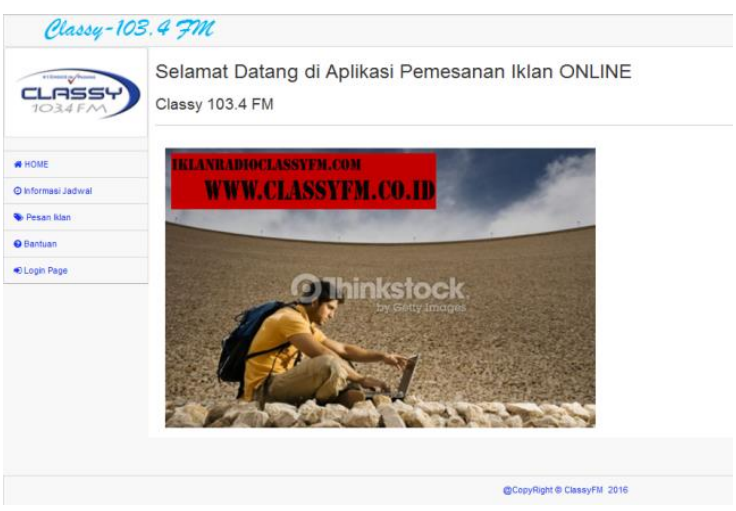

Gambar 8. Halaman Utama User

\section{B. Halaman Login}

Halaman login merupakan halaman yang digunakan oleh costumer/pelanggan, marketing dan pemimpin untuk masuk kedalam sistem dengan hak akses yang berbeda-beda.

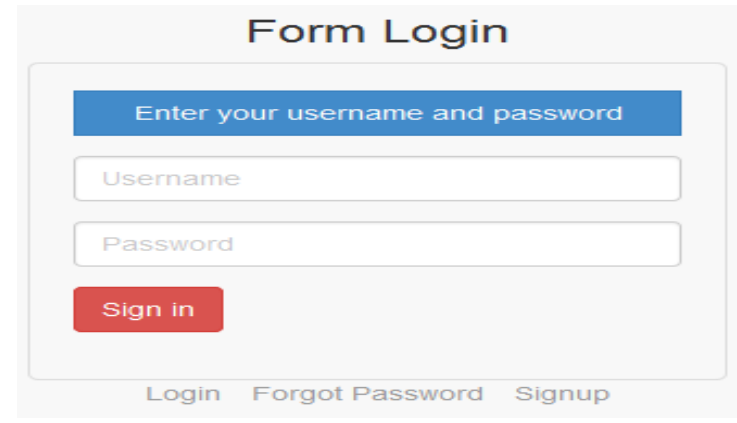

Gambar 9. Halaman Login

\section{Halaman Daftar Pelanggan}

Merupakan halaman untuk pengunjung mendaftar sebagai pelanggan untuk memesan iklan.Pendaftaran pelanggan bertujuan agar pelanggan memiliki akun untuk masuk kedalam aplikasi sistem informasi ini. Gambar 10 merupakan halaman daftar pelanggan.

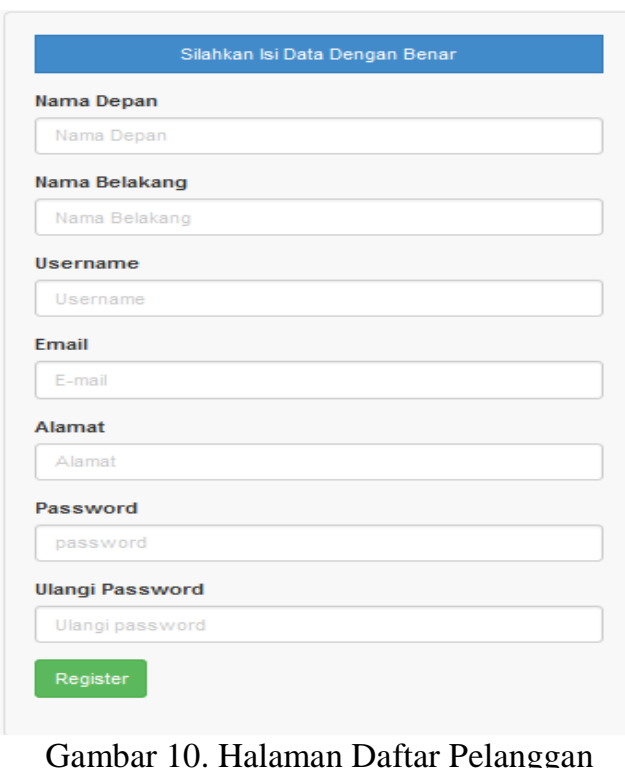

\section{Halaman Pesan Iklan}

Halaman ini berfungsi sebagai halaman pemesanan iklan berdasarkan jenis iklan yang ada. Terdapat 3 jenis iklan yang mana terlihat seperti Gambar 11.

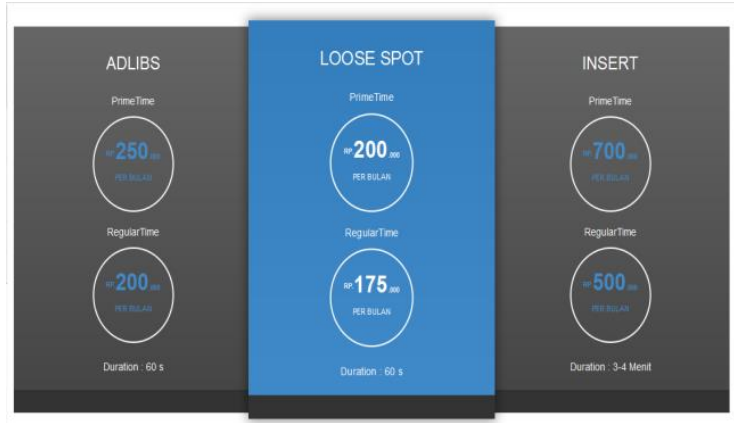

Gambar 11. Halaman Pesan Iklan

\section{E. Halaman Input Pemesanan Iklan}

Pada halaman ini pelanggan menginputkan data tentang pemesanan iklan yang dilakukan berdasarkan jenis iklan yang dipilih seperti yang terlihat pada Gambar 12.

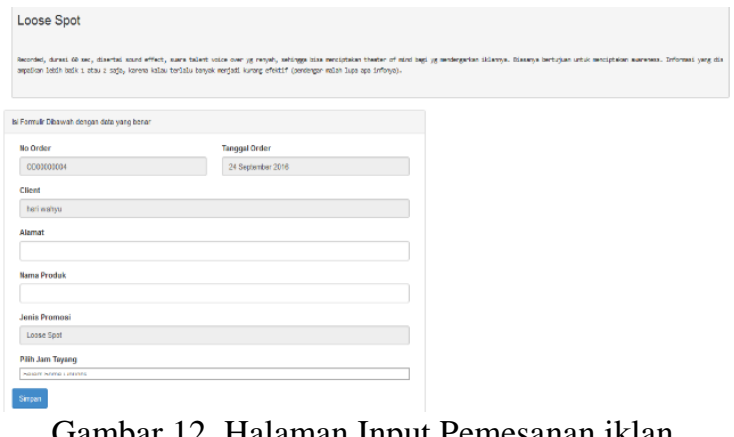

Gambar 12. Halaman Input Pemesanan iklan 


\section{F. Halaman Utama Marketing}

Halaman utama marketing merupakan halaman yang diakses oleh seorang marketing menggunakan akun yang dimiliki oleh marketing tersebut.pada halaman marketing, marketing bertugas memeriksa atau mengkonfirmasi atau memproses pemesanan iklan yang dilakukan oleh pelanggan.

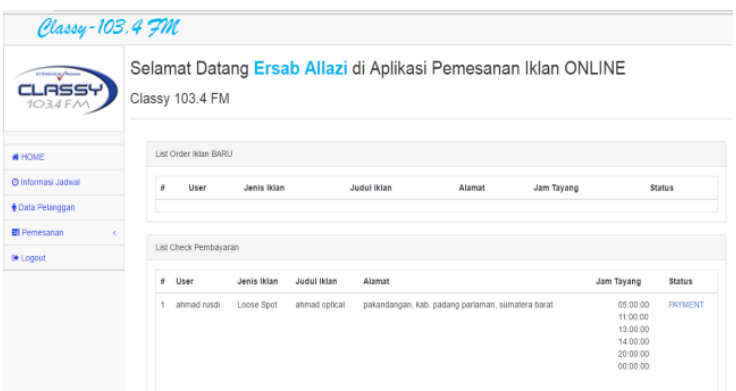

Gambar 13. Halaman Utama Marketing

\section{G. Halaman Informasi Jadwal}

Halaman ini menampilkan jadwal-jadwal iklan yang tersedia pada radio, terdapat 2 jenis waktu yang ada pada pemesanan radio yang dapat dilihat sepeti Gambar 14. Pada tabel siar atau jadwal maksimal pemutaran iklan dalam 1 jam adalah 15 iklan, jadi apabila pada saat pemesanan iklan terdapat waktu siar yang sudah penuh, maka akan keluar warning bahwasanya iklan yang dipilih penuh dan marketing akan merekomendasikan jadwal sesuai kategori pemesanan iklan yang dilakukan pelanggan.

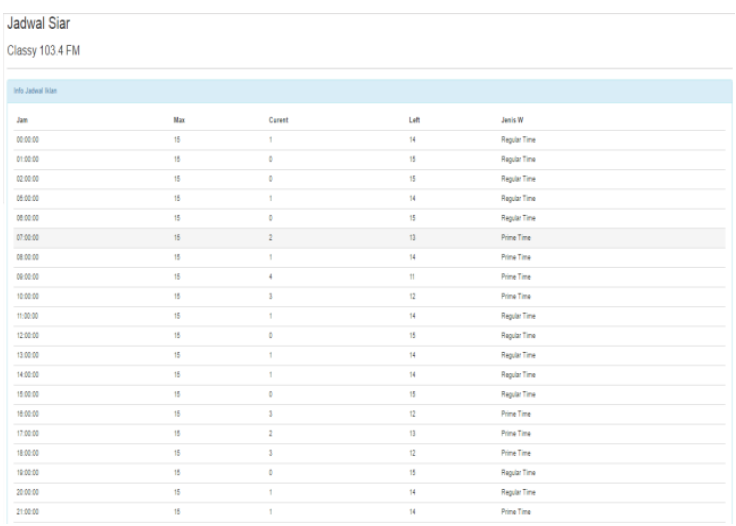

Gambar 14. Halaman Informasi Jadwal

\section{H. Halaman Data Pelanggan}

Pada menu data pelanggan terdapat data-data pelanggan yang telah melakukan pemesanan iklan. Tampilan data-data pelanggan dapat dilihat pada Gambar 15.

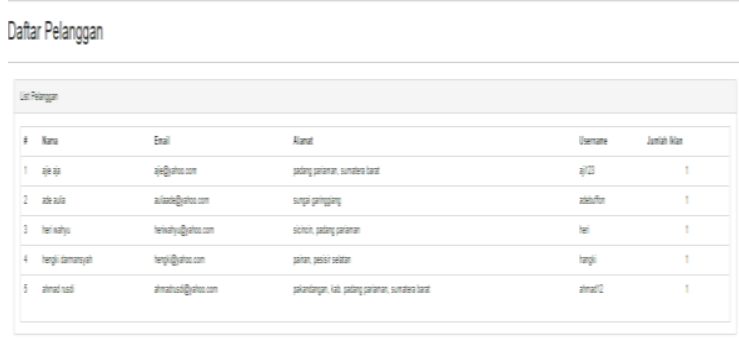

Gambar 15. Halaman Data Pelanggan

\section{Halaman Cek Pembayaran}

Pada halaman cek pembayaran berisikan semua data-data pemesanan yang telah dilakukan oleh pelanggan sebelum disetujui oleh marketing untuk penayangannya atau On Air. Dan marketing akan mengcek pembayaran yang telah dilakukan pelanggan yang mana dapat dilihat seperti Gambar 16.

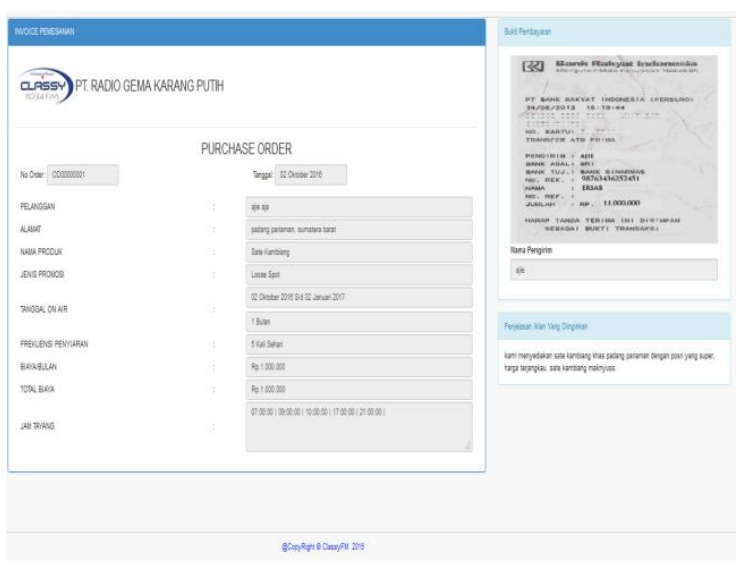

Gambar 16. Halaman Cek Pembayaran

\section{J. Halaman Utama Pimpinan}

Pimpinan bertindak sebagai user yang mengecek pemesanan iklan yang dilakukan. Peran pemimpin memantau proses transaksi yang ada agar pekerjaan marketing tidak disalah gunakan.

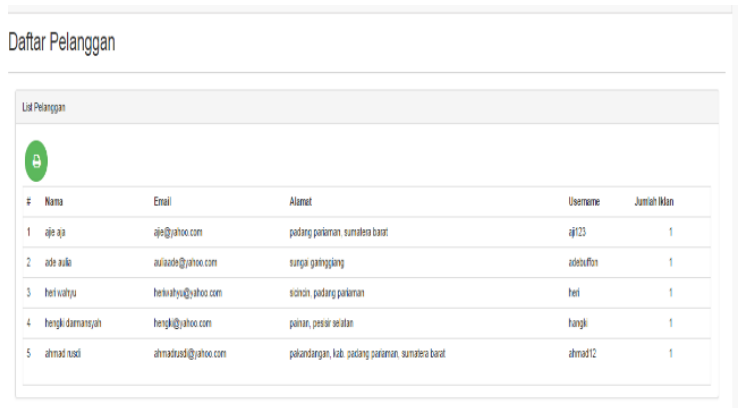

Gambar 17. Halaman Utama Pimpinan 


\section{KESIMPULAN DAN SARAN}

\section{A. Kesimpulan}

Sistem informasi penjadwalan dan pemesanan iklan radio dirancang agar dapat membantu peran seorang marketing dalam melakukan pekerjaannya sebagai seorang marketing, dan juga mempermudah costumer dalam melakukan pemesanan iklan tanpa harus bertatap muka langsung dengan marketing atau pergi ke kantor radio yang bersangkutan. Sistem informasi ini diharapkan akan menjadi sebuah aplikasi yang mampu menggantikan kerja dari marketing dalam mengiformasikan tentang pemesanan iklan pada radio tersebut.

\section{B. Saran}

Pada aplikasi sistem informasi penjadwalan dan pemesanan iklan radio ini masih sederhana, baik dari segi tampilan maupun dari segi pemesanan iklannya.Penulis berharap untuk pengembangan selanjutnya dapat memperbaiki aplikasi ini sehingga menjadi aplikasi yang sempurna dan unggul.Akan lebih baik jika aplikasi sistem informasi ini dijadikan sebagai aplikasi ang berbasiskan android, sehingga pengguna lebih mudah dalam menggunakan aplikasi ini pada perangkat mobile yang dimilikinya.

\section{REFERENSI}

[1] Jogiyanto, M.H. 2005.Pengenalan Komputer. Yogyakarta: Penerbit Andi

[2] Yuswanto, Subari. 2005, Mengolah Database dengan SQL Server 2000, Prestasi Pustaka Publisher, Surabaya.

[3] Anisya. (2013). Aplikasi Sistem Database Rumah Sakit Terpusat Pada Rumah Sakit Umum (RSU) 'Aisyiyah Padang Dengan Menerapkan Open Source (PHP-MYSQL). Jurnal Momentum ISSN: 1693-752X, 2013, 15.2. , 15 (2).

[4] Afandi, Mafut. 2014. Sistem Informasi Pemesanan Kamar di Hotel Merah Serang Berbasis Web. Universitas Muhammadiyah Ponorogo.

[5] Ibrahim, Ali. 2011. Perancangan Sistem Pemesanan Tiket Pesawat Berbasis Web. Universitas Sriwijaya.

[6] Jerry Fitzgerald (1981:5). System Analisis, New York.

[7] Kadir, Abdul. 2003. Pengenalan Sistem Informasi. Yogyakarta : Andi Yogyakarta.

[8] Ladjamudin, Albahra Bin. 2005. Konsep Sistem Basis Data dan Implementasinya. Yogyakarta: Graha Ilmu.

[9] Muharam, Candra Lesmana. 2012. Sistem Informasi Pemasangan Iklan di Radio Morista
FM Berbasis Web. Universitas Komputer Indonesia.

[10] Meiliana, Dkk. 2014.Analisis dan Perancangan Sistem Informasi Penjadwalan dan Manajemen Training pada Software Laboratory Center Universitas Bina Nusantara. Unversitas Bina Nusantara : Jakarta Barat.

[11] Nugroho, Arifin Adi. 2010. Sistem Informasi Pemesanan Penggunaan Lapangan Futsal Berbasis Web. Universitas Diponegoro: Semarang.

[12] Oetomo, Budi Sutedjo Dharma. 2002. Perencanaan dan Pengembangan Sistem Informasi. Edisi I. ANDI Yogyakarta.

[13] Poetra, Arief Rahardjo. (2013). Aplikasi Pemasangan Iklan di Media Cetak Berbasis Web Dengan Menggunakan PHP dan MySQL. Universitas Pembangunan Nasional "Veteran". Jawa Timur.

[14] Simarmata, Janner. 2007. Perancangan Basis data.Andi.Yogyakarta.

[15] Witarto.(2004). Memahami Sistem Informasi, Informatika, Bandung.

[16] Wilyanto, Willy. (2015). Pembuatan Sistem Informasi Penjadwalan dan Pemesanan Sewa BUS PO. Son Aji Dengan PHP. Amikom Yogyakarta.

[17] Wibowo, Beni. (2014). Rancangan Bangun Sistem Informasi Reservasi Sewa Kamar Hotel Berbasis Web. Universitas STIKUBANK. Semarang 